\title{
LIXIVIAÇÃO DO FUNGICIDA TRIADIMENOL EM MACROLISÍMETROS DE LATOSSOLOS DA REGIÃO DE LAVRAS-MG ${ }^{1}$
}

\author{
Leaching of the fungicide triadimenol in macrolysimeters of two latosols from Lavras-MG
}

\author{
Cristiane Jorge Bastos ${ }^{2}$, Renê Luís de Oliveira Rigitano ${ }^{3}$, José Maria de Lima ${ }^{4}$, Nélio Ricardo Amaral Castro ${ }^{5}$
}

\begin{abstract}
RESUMO
Investigou-se a lixiviação do fungicida triadimenol em macrolisímetros contendo material indeformado de dois solos representativos da região de Lavras-MG, um Latossolo Vermelho distroférrico (LVdf) e um Latossolo Vermelho-Amarelo distrófico (LVAd), em condições de campo. Uma formulação granulada do composto (Photon ${ }^{\circledR} 60 \mathrm{GR}$ ) foi aplicada a $5 \mathrm{~cm}$ de profundidade nos solos, simulando-se o uso de matraca, em lisímetros de $1,0 \mathrm{~m}$ de diâmetro e profundidade de 0,45 e 0,90 m, no início da estação chuvosa. Durante os cinco meses seguintes, a água percolada nos lisímetros foi coletada e analisada com relação à concentração de resíduos de triadimenol. Estes foram extraídos por meio de partições sucessivas com diclorometano, sendo posteriormente determinados por cromatografia gás-líquido, com detector de captura de elétrons. Os resultados mostraram uma baixa mobilidade do composto nos solos, o que foi atribuído à sua alta lipofilicidade e, conseqüentemente, alta sorção na matéria orgânica dos solos. Essa sorção restringiu a lixiviação do composto nos solos, de tal forma que as quantidades totais de resíduos transportados a profundidades abaixo de 0,90 $\mathrm{m}$, durante todo o período chuvoso, foi estimada em menos de $0,3 \%$ da quantidade aplicada, não havendo diferenças marcantes entre os solos. Foi estimado que, ao final do período chuvoso, uma fração apreciável de resíduos de triadimenol persistia nos lisímetros, devido à lenta degradação do composto nos solos.
\end{abstract}

Termos para indexação: Produto fitossanitário, degradação, lisímetro, lençol freático.

\begin{abstract}
The leaching of the fungicide triadimenol was investigated in macrolysimeters containing undisturbed soil material of a distroferric Red Latosol and of a distrofic Yellow Red Latosol, under field conditions. A granular formulation of the pesticide was applied at the recommended rate, at 5-cm depth, in soil columns of $1.0 \mathrm{~m}$ diameter and 0.45 and $0.90 \mathrm{~m}$ long, at the beginning of the rainy season. The volume of percolated water in each lysimeter was measured during the following five months, with samples of this water being periodically taken for analysis of residues of the chemical. The pesticide residues were extracted through partitioning with dichloromethane, and subsequently measured by gas-liquid chromatography, with electron capture detector. The mobility of triadimenol was shown to be very low, and was attributed to its high sorption to the organic matter of the soils. This sorption accounted for the leaching of less than $0.3 \%$ of the applied dose, below $0.90 \mathrm{~m}$. Triadimenol was still found in the leaching water at the end of the experiment, and an appreciable portion of the applied dose was estimated to remain in the lysimeters by the end of the rainy season. The leaching of the chemical did not differ markedly between the soils.
\end{abstract}

Index terms: Pesticide, degradation, lysimeter, groundwater.

(Recebido para publicação em 22 de setembro de 2004 e aprovado em 4 de maio de 2005)

\section{INTRODUÇÃO}

A agricultura voltada para o aumento de produtividade tem incentivado o crescimento no uso de produtos químicos biocidas, genericamente chamados de produtos fitossanitários, para a proteção das lavouras contra insetos-praga, doenças e plantas daninhas. Embora esses produtos evitem perdas na produtividade das culturas, eles podem causar contaminações nos agroecossistemas, visto que muitos deles são tóxicos a organismos não-alvo, incluindo os seres humanos.

Os recursos hídricos são particularmente susceptíveis à contaminação com resíduos de produtos fitossanitários, pois tem sido demonstrado que esses resíduos podem ser arrastados pela água de enxurrada, bem como pela água que percola o solo (lixiviação). Embora os casos de contaminação de recursos hídricos com resíduos desses produtos tenham sido associados com maior frequiência ao transporte superficial dos compostos, relatos da contaminação da água de poços e minas, em decorrência da lixiviação dos resíduos, são abundantes na literatura (DOMAGALSKI \& DUBROVSKY, 1992; FLURY, 1996; USEPA, 1988, 1990).

\footnotetext{
1 Trabalho financiado pela FAPEMIG. Parte da dissertação apresentada à Universidade Federal de Lavras/UFLA pelo primeiro autor, como um dos requisitos do curso de Mestrado em Agroquímica/Agrobioquímica.

${ }^{2}$ Engenheira Química, M. Sc., Universidade Federal de Lavras/UFLA - Caixa Postal 3037 - 37.200-000 - Lavras, MG.

${ }^{3}$ Engenheiro Agrônomo, Ph.D., Professor Titular do Departamento de Entomologia/UFLA, bolsista do CNPq

${ }^{4}$ Engenheiro Agrônomo, Ph.D., Professor Adjunto do Departamento de Ciência do Solo/UFLA, bolsista do CNPq.

${ }^{5}$ Engenheiro Agrônomo, M.Sc., Doutorando do Departamento de Entomologia/UFLA.
} 
A aplicação de produtos fitossanitários no solo, visando ao controle de insetos e microrganismos prejudiciais à cultura do cafeeiro, é uma prática muito comum entre os cafeicultores de todo o País. Dentre esses produtos destaca-se o fungicida triadimenol, utilizado para o controle do fungo causador da ferrugem do cafeeiro.

O triadimenol é um composto bastante lipofílico, com coeficiente de partição entre octanol e água $\left(\log \mathrm{K}_{\mathrm{ow}}\right)$ de 3,2 (BROMILOW et al., 1999a). Compostos lipofílicos apresentam altos coeficientes de adsorção na matéria orgânica do solo e, portanto, sua lixiviação em solos é esperada ser relativamente baixa (BRIGGS, 1981; NICHOLLS, 1988). Por outro lado, a degradação do triadimenol em solos europeus (BROMILOW et al., 1999b) e brasileiros (CARVALHO et al., 2002) revelou-se muito lenta, com valores de meia-vida de até 294 dias nesses últimos. Conforme apontado por Carvalho et al. (2002), apesar dos valores de coeficiente de adsorção do triadimenol nos solos estudados terem se revelado relativamente altos (acima de 3,0), a lenta degradação do composto poderia resultar em apreciável lixiviação do mesmo em condições de campo.

Petrovic et al. (1994) investigaram a lixiviação do triadimenol em lisímetros com $37 \mathrm{~cm}$ de profundidade, contendo material de solo arenoso com baixo teor de matéria orgânica. A aplicação do produto no início do mês de setembro resultou na presença de resíduos no lixiviado até o mês de junho do ano seguinte. Matrangolo (1999) investigou a lixiviação do triadimenol em colunas de 5 e 10 $\mathrm{cm}$ de material de solo desestruturado, coletado da camada superficial de um Latossolo da região de Viçosa-MG. Resíduos de triadimenol na água percolada nas colunas de $10 \mathrm{~cm}$ não foram detectados, tendo sido concluído que a lixiviação do composto em solos é muito baixa, não colocando em risco a contaminação do lençol freático daquele solo, em condições de campo. Contudo, a quantidade de chuva simulada nesse estudo foi de apenas $60 \mathrm{~mm}$. Em vista dos índices anuais de precipitação pluviométrica serem muito maiores em regiões de cultivo do cafeeiro e, em vista da alta estabilidade do triadimenol em solos também usados para cafeicultura, conforme observado por Carvalho et al. (2002), fica clara a possibilidade de lixiviação do composto a maiores profundidades.

Desse modo, conduziu-se este trabalho com o objetivo de investigar a lixiviação do fungicida triadimenol em dois latossolos representativos da região de Lavras-
MG. Para tal, foram utilizados lisímetros de grandes dimensões, contendo material indeformado desses solos, de forma a permitir uma avaliação dos riscos de contaminação da água subterrânea nos mesmos, com resíduos desse fungicida, em condições próximas àquelas de áreas de cultura. Adicionalmente, objetivou-se subsidiar futuros estudos sobre o desenvolvimento ou validação de modelos de simulação da lixiviação de produtos fitossanitários em solos brasileiros.

\section{MATERIALEMÉTODOS}

A lixiviação do triadimenol foi investigada em lisímetros do Departamento de Ciência do Solo da Universidade Federal de Lavras- UFLA. Foram utilizadas colunas contendo material de solo das classes Latossolo Vermelho distroférrico (LVdf) e Latossolo VermelhoAmarelo distrófico (LVAd). As colunas de solo foram obtidas em 1983, de solos localizados no campus da UFLA, usando-se a metodologia descrita por Souza (1983). Tais colunas de solos foram coletadas em cilindros de aço de $1,0 \mathrm{~m}$ de diâmetro e profundidade de 0,45 e $0,90 \mathrm{~m}$, mantendo-se a estrutura original dos solos.

Algumas das propriedades físico-químicas dos solos estudados, determinadas por ocasião da coleta das unidades de solo, são mostradas na Tabela 1.

Para a implantação do experimento, as colunas de solo foram submetidas à medições de sua condutividade hidráulica saturada, as quais foram realizadas com o Permeâmetro de Ghelph, sendo utilizadas colunas de água de 5 e $10 \mathrm{~cm}$.

A aplicação do fungicida foi feita no início do período chuvoso na região de Lavras-MG, em 03 de novembro de 2000. Foi utilizado o produto comercial Photon $^{\circledR} 60$ GR (60 g de triadimenol/kg), o qual é formulado em grânulos para a aplicação no solo. Em cada coluna foram aplicados $14 \mathrm{~g}$ da formulação, quantidade essa estabelecida com base nas recomendações feitas pelos fabricantes, para cafeeiros adultos, assumindo-se a área do lisímetro equivalente a uma cova de cafeeiro. Por ocasião da aplicação, procedeu-se a remoção da vegetação nas colunas, as quais foram mantidas sem a vegetação durante todo o experimento. O produto foi aplicado simulando-se uma aplicação com matraca, tendo sido incorporado a $5 \mathrm{~cm}$ de profundidade, em sete pontos ( $2 \mathrm{~g} /$ ponto). Em função do número limitado de lisímetros disponibilizados para o presente trabalho, foram conduzidas duas repetições para a profundidade de $0,45 \mathrm{~m}$ e três repetições para a profundidade de $0,90 \mathrm{~m}$.

Ciênc. agrotec., Lavras, v. 29, n. 4, p. 767-774, jul./ago., 2005 
TABELA 1 - Composição granulométrica, teores de carbono, matéria orgânica, óxido de ferro e valores de pH do Latossolo Vermelho distroférrico (LVdf) e do Latossolo Vermelho-Amarelo distrófico (LVAd), de acordo com Souza (1983).

\begin{tabular}{|c|c|c|c|c|c|c|c|c|c|}
\hline \multirow[t]{2}{*}{ Solo } & \multirow{2}{*}{$\begin{array}{l}\text { Profundidade } \\
\text { (cm) }\end{array}$} & \multicolumn{3}{|c|}{ Textura } & \multirow{2}{*}{$\begin{array}{c}\mathrm{C} \\
(\%)\end{array}$} & \multirow{2}{*}{$\begin{array}{c}\text { M.O.* } \\
(\%)\end{array}$} & \multirow{2}{*}{$\mathrm{Fe}_{2} \mathbf{O}_{3} * *$} & \multicolumn{2}{|c|}{ pH } \\
\hline & & Areia & Silte & Argila & & & & $\mathrm{H}_{2} \mathrm{O}$ & KCl 1M \\
\hline \multirow{3}{*}{ LVdf } & $0-8$ & 9 & 24 & 67 & 2,4 & 4,2 & 26,3 & 5,2 & 5,7 \\
\hline & $8-52$ & 8 & 24 & 68 & 0,8 & 1,3 & 28,6 & 5,0 & 5,2 \\
\hline & $52-100$ & 8 & 20 & 72 & 0,6 & 1,1 & 28,8 & 5,9 & 5,3 \\
\hline \multirow{3}{*}{ LVAd } & $0-40$ & 36 & 5 & 59 & 1,8 & 3,2 & 8,2 & 4,2 & 5,3 \\
\hline & $40-70$ & 26 & 3 & 71 & 0,6 & 1,1 & 9,8 & 4,2 & 5,1 \\
\hline & $70-93$ & 32 & 5 & 63 & 0,5 & 0,8 & 9,5 & 4,5 & 5,1 \\
\hline
\end{tabular}

$* \mathrm{MO}=\mathrm{C} \times 1,724 ; * *$ Obtido pelo extrato sulfúrico.

A água percolada nos lisímetros foi coletada em recipientes de aço inox, com $15 \mathrm{~L}$ de capacidade, acoplados à tubulação proveniente dos lisímetros. As amostras foram coletadas até o final do período chuvoso, por volta de 150 dias após a aplicação. Por ocasião das coletas, o volume de água percolada foi medido e uma amostra $(500 \mathrm{~mL})$ foi separada para análise. Por volta dos 190 dias após a aplicação, procedeu-se a adição diária de $15 \mathrm{~L}$ de água aos lisímetros, durante duas semanas; o volume de água percolada nesses lisímetros foi diariamente medido e, a intervalos de 2 ou 3 dias, uma amostra foi coletada para análise de resíduos.

A metodologia utilizada para a determinação do triadimenol nas amostras de água foi baseada naquela adaptada por Carvalho et al. (2002), a partir de metodologias desenvolvidas por outros autores. De cada amostra de água foi separada uma sub-amostra de $100 \mathrm{~mL}$, que foi submetida à extração dos resíduos, em funil de separação, através de três partições sucessivas com $50 \mathrm{~mL}$ de diclorometano cada uma, passando-se as fases orgânicas em cerca de $20 \mathrm{~g}$ de sulfato de sódio anidro. Após eliminação do diclorometano em rotavapor, com banho a $45^{\circ} \mathrm{C}$, os resíduos foram transferidos, em acetona, para tubos de centrífuga graduados, ajustando-se o volume final para $2 \mathrm{~mL}$. A determinação quantitativa do triadimenol foi feita em cromatógrafo a gás, operando com detector de captura de elétrons $\left(\mathrm{Ni}^{63}\right)$. Utilizou-se uma coluna tipo empacotada, de vidro (1,80 $\mathrm{m}$ de comprimento e $2 \mathrm{~mm}$ de diâmetro interno), contendo 5\% de OV-101 em chromosorb W-HP 80/100. Como gás de arraste, foi utilizado o nitrogênio, com fluxo de $52 \mathrm{~mL} / \mathrm{min}$. As temperaturas de trabalho do vaporizador, coluna e detector foram $240^{\circ} \mathrm{C}, 236^{\circ} \mathrm{Ce} 260^{\circ} \mathrm{C}$, respectivamente. Nessas condições, o tempo de retenção do triadimenol foi 2 minutos e 10 segundos. O padrão analítico do triadimenol utilizado nas análises foi fornecido pela Bayer S. A., tendo especificação de pureza de 97,4\%.

Para certificação do teor de ingrediente ativo na formulação do Photon ${ }^{\circledR} 60 \mathrm{GR}$, duas amostras (10 g) foram submetidas à extração do ingrediente ativo, usando-se acetona $(100 \mathrm{~mL})$ como solvente extrator em mesa agitadora durante 1 h. Após decantação dos resíduos sólidos, retirou-se uma alíquota de $1 \mathrm{~mL}$ da solução cetônica, a qual foi apropriadamente diluída e analisada por cromatografia gás-líquido.

Para certificação da eficiência do método analítico utilizado nas determinações do triadimenol, as amostras de água foram fortificadas com o composto nas concentrações $0,05,0,5$ e $5,0 \mathrm{mg} / \mathrm{L}$, sendo subseqüentemente analisadas conforme descrito anteriormente.

Os dados diários de precipitação pluviométrica e temperatura média do ar durante todo o período experimental foram obtidos na Estação Meteorológica da UFLA, localizada a cerca de $40 \mathrm{~m}$ do local onde encontramse os lisímetros.

\section{RESULTADOS E DISCUSSÃO}

Os resultados obtidos nas medições da condutividade hidráulica saturada dos solos contidos nos diferentes lisímetros são mostrados na Tabela 2. Foi constatada grande variação entre os valores obtidos para os diferentes lisímetros do mesmo solo. Apesar disso, o solo LVdf apresentou valores médios de condutividade hidráulica maiores que o solo LVAd, o que se deve à sua estrutura mais granular, comparativamente a esse último (SOUZA, 1983). 
TABELA 2 - Valores de condutividade hidráulica saturada dos materiais de Latossolo Vermelho distroférrico (LVdf) e Latossolo Vermelho-Amarelo distrófico (LVAd) contidos em colunas de lisímetro.

\begin{tabular}{cccc}
\hline Solo & $\begin{array}{c}\text { Profundidade } \\
(\mathbf{m})\end{array}$ & $\mathbf{N}^{\mathbf{0}}$ do lisímetro & $\begin{array}{c}\text { Condutividade } \\
(\mathbf{m m} / \mathbf{h})\end{array}$ \\
\hline \multirow{3}{*}{ LVdf } & 0,45 & 34 & 194,6 \\
& 0,45 & 40 & 111,6 \\
& 0,90 & 13 & 105,3 \\
& 0,90 & 16 & 81,6 \\
& 0,90 & 22 & 169,4 \\
\hline \multirow{2}{*}{ LVAd } & 0,45 & 35 & 96,6 \\
& 0,45 & 41 & 64,5 \\
& 0,90 & 20 & 57,3 \\
& 0,90 & 29 & 194,6 \\
\hline
\end{tabular}

Os resultados obtidos nos testes de recuperação do triadimenol mostraram valores médios de recuperação de $98,2,94,0$ e $95,7 \%$, para as concentrações $0,05,0,5$ e 5,0 $\mathrm{mg} / \mathrm{L}$, respectivamente. Uma vez que a eficiência foi próxima a $100 \%$, os resultados obtidos nas análises das amostras de água provenientes dos lisímetros não foram corrigidos. O limite mínimo de determinação do triadimenol em amostras de água, de acordo com a metodologia utilizada, foi estimado em $0,01 \mathrm{mg} / \mathrm{L}$.

As análises das amostras da formulação de Photon ${ }^{\circledR}$ $60 \mathrm{GR}$ revelaram um teor médio de $62 \mathrm{~g}$ de ingrediente ativo por $\mathrm{kg}$, valor muito próximo daquele especificado pelo fabricante. Sendo assim, para os cálculos das quantidades totais de resíduos percolados nos diferentes lisímetros, em relação à quantidade aplicada do composto, foi considerado o teor de ingrediente ativo especificado na formulação.

Os dados climatológicos obtidos durante o período experimental estão expostos na Figura 1, arranjados de maneira semanal.

Os resultados obtidos nas análises da água percolada nos lisímetros de $0,45 \mathrm{~m}$ tratados com triadimenol são mostrados na Figura 2.

Em ambos os solos foram encontrados resíduos de triadimenol já nas primeiras amostras de água percolada, em maiores concentrações nas amostras coletadas do LVAd em relação àquelas do LVdf. Resíduos de triadimenol foram subseqüentemente encontrados em todas as amostras de água analisadas, revelando lenta lixiviação do composto nos dois solos estudados. As quantidades totais de resíduos transportados à profundidades abaixo de $0,45 \mathrm{~m}$, ao final do período de 150 dias após a aplicação, foram estimadas em apenas 6,7\% (LVAd) e 2,1\% (LVdf), em relação à quantidade aplicada do triadimenol. A adição de $15 \mathrm{~L}$ de água/dia a cada um dos lisímetros, durante duas semanas, a partir dos 150 dias desde a aplicação do composto, resultou em contínua remoção dos resíduos (Figura 3), confirmando a lenta e persistente lixiviação dos resíduos.

No caso dos lisímetros de $0,90 \mathrm{~m}$, não foram detectados resíduos na água percolada naqueles do LVdf, até o final do período de coleta. Com relação aos lisímetros do LVAd, em dois deles foram detectados apenas traços do triadimenol e somente nas últimas coletas. No outro lisímetro do LVAd, foram detectados resíduos na água coletada a partir dos 20 dias desde a aplicação, com posterior detecção deles até o final do período de coleta. A lixiviação atípica nesse lisímetro parece ter sido resultante de fluxo preferencial mais intenso da água no mesmo, tendo como conseqüência o arraste mais intenso de resíduos após as primeiras chuvas, em condições de não-equilíbrio. Mesmo nesse lisímetro, a quantidade total que foi transportada à profundidades abaixo de $0,90 \mathrm{~m}$, ao final do período de 150 dias desde a aplicação, foi estimada em torno de $0,3 \%$ da quantidade total aplicada. 


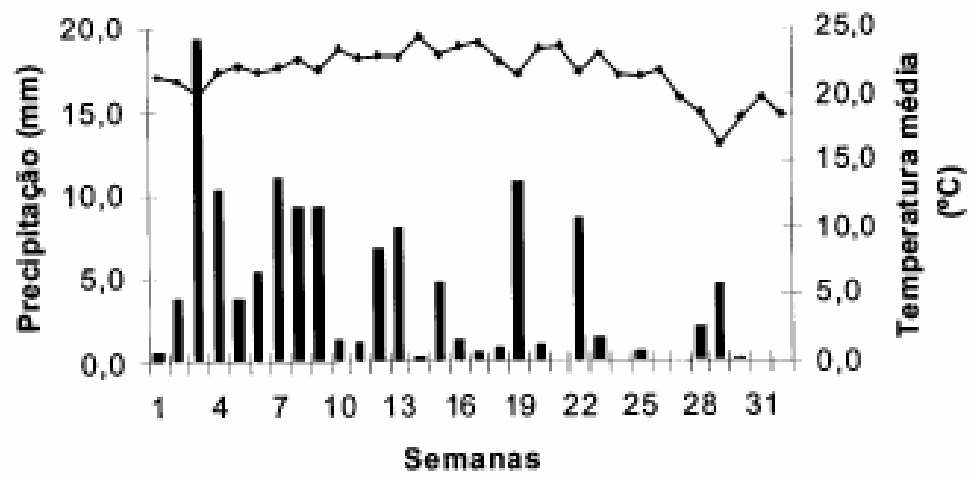

FIGURA 1 - Precipitação (mm) e temperatura média $\left({ }^{\circ} \mathrm{C}\right)$ semanais, no local do estudo, no período de 31/10/2000 a 11/06/2001. UFLA, Lavras, MG.
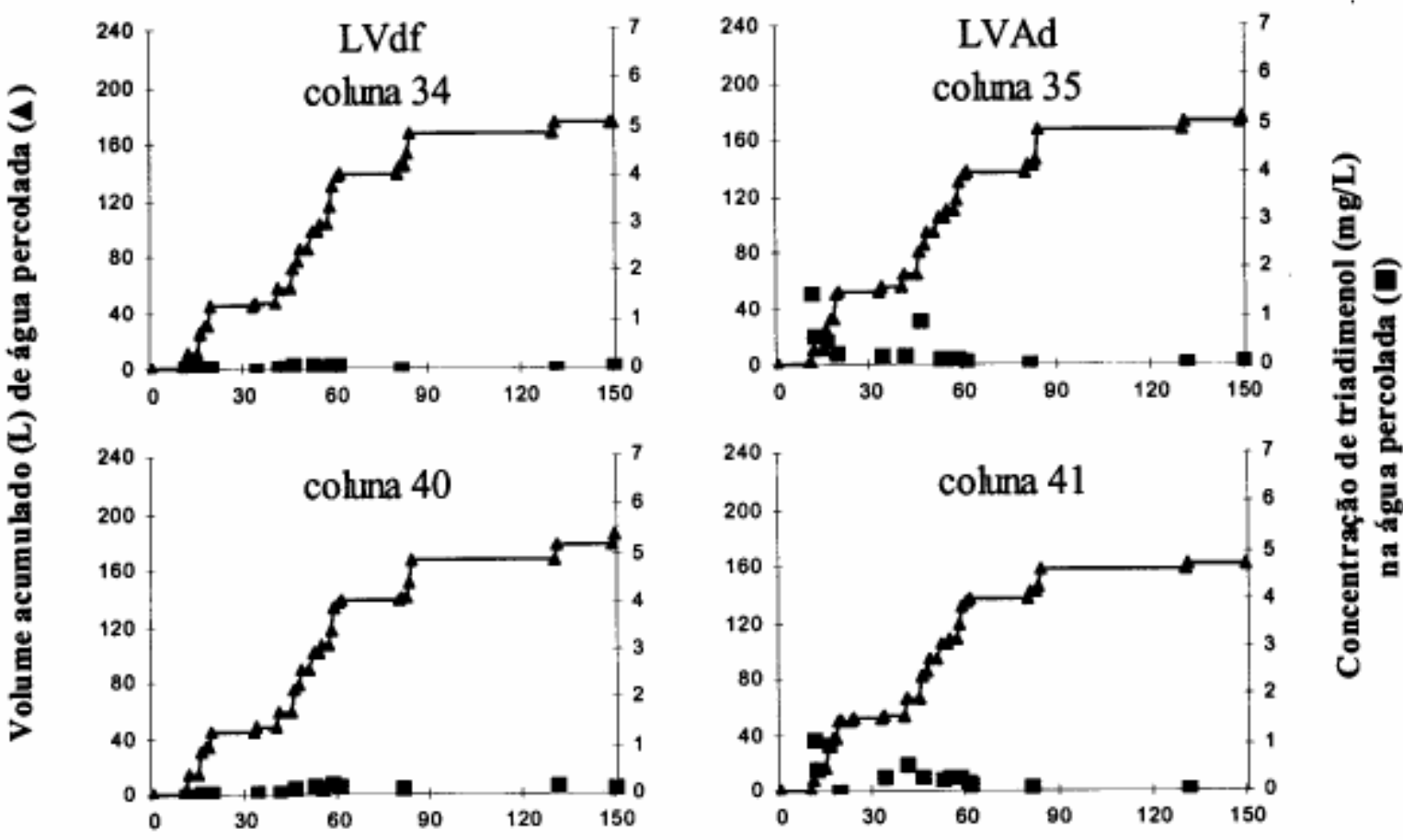

Dias após aplicação

FIGURA 2 - Concentração de resíduos de triadimenol na água percolada nos lisímetros de 0,45 m do Latossolo Vermelho distroférrico (LVdf) e Latossolo Vermelho-Amarelo distrófico (LVAd). UFLA, Lavras, MG. 

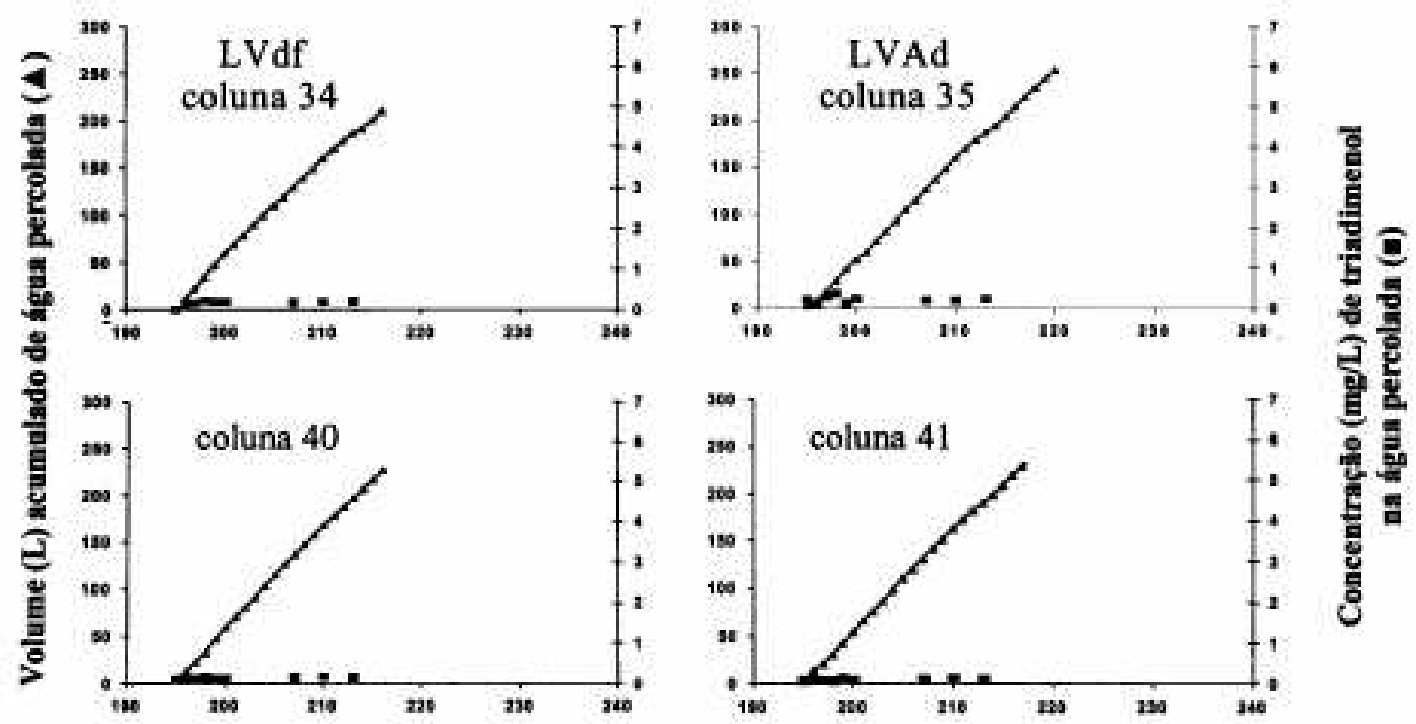

\section{Dias após a aplicação}

FIGURA 3 - Percolação de água adicionada nos lisímetros de 0,45 m do Latossolo Vermelho distroférrico (LVdf) e Latossolo Vermelho-Amarelo distrófico (LVAd) e concentração do triadimenol na água percolada. UFLA, Lavras, MG.

Os resultados descritos anteriormente mostraram que o triadimenol possui uma baixa mobilidade nos solos estudados. Indicam ainda, que a lixiviação do composto observada nas colunas de $0,45 \mathrm{~m}$, especialmente naquelas do LVAd, ocorreu, ao menos em parte, em situação de nãoequilíbrio, logo após as primeiras chuvas; após essas, com a interação mais completa do triadimenol com os colóides do solo, a lixiviação teria sido sensivelmente reduzida, razão pela qual os resíduos não apareceram nas colunas de 0,90 $m$ do LVdf ou apareceram em concentrações muito baixas naquelas de $0,90 \mathrm{~m}$ do LVAd. A baixa mobilidade do triadimenol é atribuída à elevada sorção do composto na matéria orgânica dos solos e não à sua alta degradação nos mesmos. O triadimenol apresenta valor de $\log \mathrm{K}_{\mathrm{ow}}$ de 3,2 (BROMILOW et al., 1999b), sendo, portanto, bastante lipofílico. Com base nas equações de Briggs (1981) e no teor de matéria orgânica no horizonte $\mathrm{A}$ dos solos estudados, os valores calculados de $\mathrm{K}_{\mathrm{d}}$ do triadimenol no LVdf e LVAd são respectivamente 4,7 e 3,9. Valores de $\mathrm{K}_{\mathrm{d}}$ dessa magnitude restringem a mobilidade de produtos fitossanitários em solos, devido à concentração muito maior do composto sorvida nos colóides do que na solução do solo, ao menos em situação de equilíbrio. A lixiviação um pouco mais intensa do triadimenol no LVAd em relação ao LVdf, conforme observada nos lisímetros de 0,45 m e 0,90 $\mathrm{m}$, apresentou-se coerente com o menor valor calculado de $\mathrm{K}_{\mathrm{d}}$ no LVAd. Como a condutividade hidráulica do LVdf revelou-se, em média, superior àquela do LVAd, pode ser inferido que a variação na sorção do triadimenol nesses solos foi mais significativa do que a variação na condutividade hidráulica, como determinantes da lixiviação do triadimenol nos mesmos.

Carvalho et al. (2002) investigaram a degradação do triadimenol em solos da região de Lavras-MG, tendo encontrado valores estimados de meia-vida do composto em torno de 220 e 290 dias, em amostras dos mesmos LVAd e LVdf usados no presente trabalho, respectivamente. Tais resultados reforçam a acertiva feita anteriormente de que a baixa (lenta) lixiviação do triadimenol nesses solos resulta da elevada sorção do composto e não da sua rápida degradação nos mesmos.

Matrangolo (1999) investigou a lixiviação do triadimenol, em condições de laboratório, em material de solo (LVA) desestruturado, contido em tubos de PVC de 5 e $10 \mathrm{~cm}$ de altura. Foi observado que a simulação de $60 \mathrm{~mm}$ de chuva sobre as colunas de solo resultou na percolação de quantidades totais inferiores a $1 \%$ da dose aplicada nas colunas de $5 \mathrm{~cm}$, não tendo sido detectados resíduos do composto na água percolada nas colunas de $10 \mathrm{~cm}$. A maior lixiviação do triadimenol observada no presente estudo é 
atribuída à maior precipitação pluviométrica durante o período experimental deste, e ao fato daquele autor ter aplicado o composto puro dissolvido em pequeno volume de água e, portanto, a interação do triadimenol com os colóides do solo teria sido inicialmente mais completa naquele estudo.

Os resultados obtidos no presente trabalho mostraram uma baixa lixiviação do triadimenol nos solos estudados. Como esses solos são tipicamente profundos, com o lençol freático localizado a vários metros de profundidade, os riscos de contaminação da água desse lençol e eventualmente de poços ou minas d'água, seriam mínimos ou desprezíveis. Ficou evidenciado, no entanto, que parte dos resíduos pode ser lixiviada mais rapidamente, por ocasião de chuvas intensas após a aplicação, devido ao tempo insuficiente para completa interação do triadimenol com a matéria orgânica do solo. Evidentemente que essa forma de transporte depende do tipo de solo, do clima e da época de aplicação do fungicida, fatores estes que precisam ser melhores investigados para se ter uma idéia melhor sobre a importância dessa forma de transporte. Após a interação do triadimenol com os colóides do solo, a sua lixiviação revelou-se bastante baixa, porém, foram detectados resíduos do fungicida, embora em quantidades muito baixas em relação à dose aplicada, a profundidades abaixo de $0,90 \mathrm{~m}$, no caso do Latossolo Vermelho-Amarelo distrófico. Devido à alta estabilidade do triadimenol e à prática de aplicações anuais do composto, como no caso da cultura do cafeeiro, estudos adicionais sobre o efeito de aplicações repetidas do composto sobre sua lixiviação em solos fazem-se necessários.

\section{CONCLUSÕES}

A aplicação da formulação granulada do fungicida triadimenol (Photon ${ }^{\circledR} 60 \mathrm{GR}$ ) em macrolisímetros de solos das classes Latossolo Vermelho distroférrico e Latossolo Vermelho-Amarelo distrófico, no início do período chuvoso, resultou na lixiviação de quantidades relativamente baixas de resíduos do composto (menos de $0,3 \%$ da dose aplicada) a profundidades abaixo de $0,90 \mathrm{~m}$, ao final do período chuvoso, em ambos os solos. Diferenças marcantes entre os solos, com relação à lixiviação do composto, não foram observadas. Os resíduos de triadimenol apresentaram baixa mobilidade e lenta degradação nos solos estudados. A baixa mobilidade do composto é atribuída à sua alta lipofilicidade e, conseqüentemente, alta sorção na matéria orgânica do solo.
Em função da alta estabilidade do triadimenol nos solos aqui estudados, o efeito de aplicações anuais sucessivas do composto sobre sua lixiviação precisa ser investigado para melhor avaliação dos riscos de contaminação do lençol freático desses solos com resíduos desse fungicida.

\section{REFERÊNCIAS BIBLIOGRÁFICAS}

BRIGGS, G. G. Theoretical and experimental relationship between soil adsorption, octanol-water partition coefficients, water solubilities, bioconcentration factors, and the parachlor. Journal of Agriculture and Food Chemistry, Washington, v. 29, n. 6, p. 1050-1059, Nov./ Dec. 1981.

BROMILOW, R. H.; EVANS, A. A.; NICHOLLS, P. H. Factors affecting degradation rates of five triazole fungicides in two soil types: I. laboratory incubations. Pesticide Science, Oxford, v. 55, n. 12, p. 1129-1134, Dec. 1999a.

BROMILOW, R. H.; EVANS, A. A.; NICHOLLS, P. H. Factors affecting degradation rates of five triazole fungicides in two soil types: II. field studies. Pesticide Science, Oxford, v. 55, n. 12, p. 1135-1142, Dec. 1999b.

CARVALHO, R. F. de; RIGITANO, R. L. de O.; LIMA, J. M. de. Sorção e degradação do fungicida triadimenol em solos representativos do município de Lavras-MG. Ciência e Agrotecnologia, Lavras, v. 26, n. 2, p. 332-341, mar./abr. 2002.

DOMAGALSKI, J. L.; DUBROVSKY, N. M. Pesticide residues in ground water of the San Joaquim Valley, California. Journal of Hidrology, Amsterdam, v. 130, n. 1/4, p. 299-338, Jan. 1992.

FLURY, M. Experimental evidence of transport of pesticides through field soils: a review. Journal of Environmental Quality, Madison, v. 25, n. 1, p. 25-45, Jan./Feb. 1996.

MATRANGOLO, P. F. R. Avaliação da percolação do triadimenol no solo por cromatografia gasosa e cromatografia líquida de alta eficiência. 1999. $67 \mathrm{f}$. Dissertação (Mestrado em Agroquímica) - Universidade Federal de Viçosa, Viçosa, 1999. 
NICHOLLS, P. H. Factors influencing entry of pesticides into soil water. Pesticide Science, Oxford, v. 22, n. 2, p. 123-137, 1988.

PETROVIC, A. M.; YOUNG, R. G.; SANCHIRICO, C. A.; LISK, D. J. Triadimenol in turfgrass lysimeter leachates after fall application of triadimenol and overwintering. Chemosphere, Oxford, v. 29, n. 2, p. 415-419, July 1994.

SOUZA, J. J. de. Complemento de uma bateria de lisímetros: coleta dos solos e implantação do complexo. In: ESCOLA
SUPERIOR DE AGRICULTURA DE LAVRAS. Materiais corretivos: relatório final. Lavras, 1983. p. 171-198.

U.S. ENVIRONMENTAL PROTECTION AGENCY. Protecting groundwater: pesticides and agricultural practices. Washington, 1988. (EPA, 440/6-88-001).

U.S. ENVIRONMENTAL PROTECTION AGENCY. National survey of pesticides in drinking water wells: phase I report. Washington, 1990.

Ciênc. agrotec., Lavras, v. 29, n. 4, p. 767-774, jul./ago., 2005 